\title{
Bioconcentration Factor of Polychlorinated Biphenyls and Its Correlation with UV- and IR-Spectroscopic data: A DFT based Study
}

\author{
Sangeeta Sahu ${ }^{1}$, Vishnu Kumar Sahu ${ }^{2, *}$, Anil Kumar Soni ${ }^{3}$
}

How to cite this paper: Sahu, S.,

Sahu, V. K., Soni, A. K.; Bioconcentration Factor of Polychlorinated Biphenyls and Its Correlation with UV- and IR-Spectroscopic data: A DFT based Study. Online Journal of Chemistry. 2021, 1, 1.

https://doi.org/10.31586/ojc.2021.010 101

Received: April 11, 2021

Accepted: May 18, 2021

Published: May 20, 2021

Copyright: (c) 2021 by the authors. Submitted for possible open access publication under the terms and conditions of the Creative Commons Attribution (CC BY) license (http://creativecommons.org/licenses /by/4.0/).

\author{
${ }^{1}$ Department of Chemistry, University of Lucknow, Lucknow-226007 (U.P.), India. \\ ${ }^{2}$ Department of Chemistry, Maharani Lal Kunwari Post Graduate College, Balrampur-271201 (U.P.), India. \\ ${ }^{3}$ Department of Chemistry, Shia Post Graduate College, Sitapur Road, Lucknow-226020 (U.P.), India. \\ *Correspondence: vishnukr_sahu@rediffmail.com
}

\begin{abstract}
Polychlorinated biphenyls (PCBs) are important class of persist organic pollutants that were used as a component of paints especially in printings, as plastificator of plastics and insulating materials in transformers and capacitors, heat transfer fluids, additives in hydraulic fluids in vacuum and turbine pumps. There is always a need to establish reliable procedures for predicting the bioconcentration potential of chemicals from the knowledge of their molecular structure, or from readily measurable properties of the substance. Hence, correlation and prediction of biococentration factors (BCFs) based on $\lambda_{\max }$ and vibration frequencies of various bonds viz $v(\mathrm{C}-\mathrm{H})$ and $v(\mathrm{C}=\mathrm{C})$ of biphenyl and its fifty-seven derivatives have been made. For the study, the molecular modeling and geometry optimization of the PCBs have been performed on workspace program of CAChe Pro 5.04 software of Fujitsu using DFT method. UV-visible spectra for each compound were created by electron transition between molecular orbitals as electromagnetic radiation in the visible and ultraviolet (UV-visible) region is absorbed by the molecule. The energies of excited electronic states were computed quantum mechanically. IR spectra of transitions for each compound were created by coordinated motions of the atoms as electromagnetic radiation in the infrared region is absorbed by the molecule. The force necessary to distort the molecule was computed quantum mechanically from its equilibrium geometry and thus frequency of vibrational transitions was predicted. Project Leader Program associated with CAChe has been used for multiple linear regression (MLR) analysis using above spectroscopic data as independent variables and BCFs of PCBs as dependent variables. The reliability of correlation and predicting ability of the MLR equations (models) are judged by $\mathrm{R}^{2}, \mathrm{R}^{2}$ adj, se, $\mathrm{q}^{2} \mathrm{~L} 100$ and F values. This study reflected clearly that UV and IR spectroscopic data can be used to predict BCFs of a large number of related compounds within limited time without any difficulty.
\end{abstract}

Keywords: Bioconcentration factor; CAChe; density functional theory; polychlorinated biphenyls; UV and IR spectroscopic data

\section{Introduction}

In our recent communication, we have employed semiempirical technique to predict the bioconcentration factor (BCF: the ratio of the concentration of a chemical inside an organism to the concentration in the surrounding environment) of organic compounds in fish [1]. In the present work, we present the density functional theory (DFT) [2-4] based prediction of BCF of polychlorinated biphenyls (PCBs: an important class of persist organic pollutants) [5]. PCBs were either washed down into the soil or into the water bodies $[6,7]$. From the soil, these are absorbed by the plants along with water and minerals, and from the water bodies these are taken up by aquatic plants and animals [8]. This is one of the ways in which they enter the food chain. As these chemicals are not degradable, these 
get accumulated progressively at each tropic level [9-11]. As human beings occupy the top level in any food chains, the maximum concentration of these chemicals gets accumulated in our bodies [12-16]. Fish are the principal target organisms of BCF assessment due to their relevance as food for many species including humans and the availability of standardized testing protocols $[17,18]$. However, experimental determination of BCFs is expensive and demanding if performed correctly. Hence a number of quantitative structureactivity relationship (QSAR) based study of BCFs of the PCBs were made time to time increase the probability of success and reduce the time and cost in exploring the toxicological and ecological characteristics of molecules [19-35]. Hence, correlation and prediction of bioconcentration factors (BCFs) based on $\lambda_{\max }$ and vibration frequencies of various bonds viz $v(\mathrm{C}-\mathrm{H})$ and $v(\mathrm{C}=\mathrm{C})$ of biphenyl and its fifty-seven derivatives have been made. Our interest in DFT-based prediction of BCFs was stimulated by the fact that DFT methods $[2,36]$ are capable of generating UV- and IR-spectra quite accurately.

\section{Materials and Methods}

Table 1. Biphenyl and PCB congeners with their experimental logarithmic BCF [30]

\begin{tabular}{|c|c|c|c|c|c|}
\hline S.N. & Chemical Name & $\operatorname{LogBCF}$ & S.N. & Chemical Name & $\log B C F$ \\
\hline 1 & Biphenyl & 2.64 & 30 & $2,3,3^{`}, 4,4^{`}$-pentachloro- & 5.00 \\
\hline 2 & 4-chloro- & 2.77 & 31 & 2,3,3`,4,6-pentachloro- & 5.00 \\
\hline 3 & 2,2`-dichloro- & 3.38 & 32 & 2,3',4,4',5-pentachloro- & 5.00 \\
\hline 4 & 2,3-dichloro- & 4.11 & 33 & 3,3`4,4`,5-pentachloro- & 5.81 \\
\hline 5 & 2,3`-dichloro- & 3.80 & 34 & 2,2'3,3',4,4'-hexachloro- & 5.77 \\
\hline 6 & 2,4-dichloro- & 3.55 & 35 & 2,2`3,3`,6,6'-hexachloro- & 5.43 \\
\hline 7 & 2,4'-dichloro- & 3.57 & 36 & 2,2',3,4,4`,5-hexachloro- & 5.88 \\
\hline 8 & 2,5-dichloro- & 3.89 & 37 & 2,2`3,4,4`,5`-hexachloro- & 5.39 \\
\hline 9 & 3,5-dichloro- & 3.78 & 38 & 2,2`,3,4,5,5'-hexachloro- & 5.81 \\
\hline 10 & 4,4`-dichloro- & 3.28 & 39 & 2,2`3,4`,5,6'-hexachloro- & 5.39 \\
\hline 11 & 2,2`,5-trichloro- & 4.11 & 40 & 2,2`,3,5,5`,6-hexachloro- & 5.54 \\
\hline 12 & 2,4,4 -trichloro- & 4.20 & 41 & $2,2^{\prime}, 4,4^{\prime}, 5,5^{\prime}$-hexachloro- & 5.65 \\
\hline 13 & 2,4,5-trichloro- & 4.26 & 42 & $2,2^{\prime}, 4,4^{\prime}, 6,6^{`}$-hexachloro- & 4.93 \\
\hline 14 & 2,4',5-trichloro- & 4.23 & 43 & 2,3,3`,4,4`,5-hexachloro- & 5.39 \\
\hline 15 & 2,2`3,3`'tetrachloro- & 4.23 & 44 & 2,3,3`,4,4',5'-hexachloro- & 5.39 \\
\hline 16 & 2,2`3,5'-tetrachloro- & 4.84 & 45 & 3,3`4,4`,5,5`-hexachloro- & 5.97 \\
\hline 17 & $2,2^{\prime}, 4,4^{\prime}$-tetrachloro- & 4.85 & 46 & $2,2^{\prime}, 3,3^{\prime}, 4,5,6^{`}$-heptachloro- & 5.80 \\
\hline 18 & 2,2',4,5-tetrachloro- & 5.00 & 47 & $2,2^{\prime}, 3,4,4^{`}, 5,5^{`}$-heptachloro- & 5.80 \\
\hline 19 & 2,2`4,5`-tetrachloro- & 4.84 & 48 & 2,2’,3,4,4`,5,6'-heptachloro- & 5.80 \\
\hline 20 & 2,2',5,5`-tetrachloro- & 4.63 & 49 & $2,2^{\prime}, 3,4,4^{\prime}, 5^{\prime}, 6$-heptachloro- & 5.84 \\
\hline 21 & $2,2^{\prime}, 6,6^{\prime}$-tetrachloro- & 3.85 & 50 & $2,2^{\prime}, 3,4,5,5^{\prime}, 6$-heptachloro- & 5.80 \\
\hline 22 & 2,3,4,6-tetrachloro- & 4.60 & 51 & 2,3,3`4,4`,5’,6-heptachloro- & 5.84 \\
\hline 23 & 2,3', $4^{\prime}, 5$-tetrachloro- & 4.77 & 52 & $2,2^{\prime}, 3,3^{\prime}, 4,4 ` 5,5^{`}$-octachloro- & 5.81 \\
\hline 24 & 3,3`4,4`-tetrachloro- & 4.59 & 53 & $2,2^{`}, 3,3^{`}, 4,4^{`} 5,6$-octachloro- & 5.92 \\
\hline 25 & 2,2`,3,4,5`-pentachloro- & 5.38 & 54 & 2,2`,3,3`,4,4`5,6’octachloro- & 5.92 \\
\hline 26 & 2,2'3,4',5-pentachloro- & 5.00 & 55 & $2,2^{\prime}, 3,3^{`}, 4,5,5^{`}, 6$-octachloro- & 5.88 \\
\hline 27 & $2,2^{\prime}, 3^{\prime}, 4,5^{\prime}$-pentachloro- & 5.43 & 56 & 2,2`,3,3`,5,5',6,6`octachloro- & 5.82 \\
\hline 28 & 2,2 ',4,4,5-pentachloro- & 5.00 & 57 & 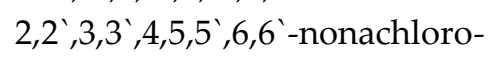 & 5.71 \\
\hline 29 & 2,2`,4,5,5`-pentachloro- & 5.40 & 58 & Decachloro- & 5.44 \\
\hline
\end{tabular}

Biphenyl and fifty-seven PCB congeners (Table 1) are the study materials for the present study. These compounds were taken from the literature with their experimental logarithmic BCF values ( $\left.\log B C F_{\exp }\right)$ fish species [30]. For the study, the 3D modeling and 
geometry optimization of all the fifty-eight compounds were performed on workspace program, active document window of CAChe pro software of Fujitsu(www.CACheSoftware.com), using the B88-PW91 GGA energy function with the DZVP basis set [37-41]. The energies of excited electronic states were computed quantum mechanically. UV-visible spectrum for each compound was created by electron transition between molecular orbitals as electromagnetic radiation in the visible and ultraviolet (UV-visible) region is absorbed by the molecule. After obtaining approximate minimum energy structures, the UV-visible electronic transitions of the each compound were generated by a ZINDO configuration interaction. IR spectrum of transitions for each compound was created by coordinated motions of the atoms as electromagnetic radiation in the infrared region is absorbed by the molecule. The force necessary to distort the molecule was computed quantum mechanically from its equilibrium geometry and thus frequency of vibrational transitions was obtained [42].

\section{Results and Discussion}

The general chemical structure of PCBs [5] is based upon the skeleton of biphenyl, which containing one to ten atoms of chlorine and has 12 sites viz. 1,2,3,4,5,6, $1^{\prime}, 2^{\prime}, 3^{\prime}, 4^{\prime}, 5^{\prime}$ and $6^{\prime}$ (Figure 1). The biphenyl and its fifty seven chloro-derivatives i.e. mono-, di-, tri, tetra-, penta-, hexa-, hepta-, nona- and decachlorobiphenyl are one, eight, four, ten, nine, twelve, six, five and one in number, respectively. Benzene shows three absorption bands at $184 \mathrm{~nm}$ (intense band, due to an allowed transition), $203.5 \mathrm{~nm}$ (weaker K-band, due to forbidden transition) and $254 \mathrm{~nm}$ (weaker B-band, also due to forbidden transition). When one of the hydrogen atoms of benzene $\left(\mathrm{C}_{6} \mathrm{H}_{5}-\mathrm{H}\right.$ or $\left.\mathrm{Ph}-\mathrm{H}\right)$ is replaced by phenyl group, then we get biphenyl molecule $\left(\mathrm{C}_{6} \mathrm{H}_{5}-\mathrm{C}_{6} \mathrm{H}_{5}\right.$ or $\left.\mathrm{Ph}-\mathrm{Ph}\right)$. Although biphenyl is symmetrical molecule (dipole moment, $\mu=0$ and dihedral angle between both ring planes through the interring bond $=0^{\circ}$ ), therefore, conjugation between the ring is not affected. Biphenyl thus shows a very intense absorption bands at $252 \mathrm{~nm}$ (K-band). Biphenyl derivative with chloro substitutions in ortho positions are more stable in twisted conformations (compound no. 11, 15-22, 25-29, 31, 32, 34-53, 46-58) than in planar conformation (compound no. 1-10, 12-14, 23, 24, 30, 33, 45 and 45). These suffer serious non-bonded compressions from the juxtaposed substitutions. The compounds with twisted conformations have HOMO-LUMO gap greater than $3.590 \mathrm{eV}$ and their dihedral angle is also greater than $53.3^{\circ}$. While those having planar structures have HOMO-LUMO gap lower than $3.590 \mathrm{eV}$ and their dihedral angle is either zero or equal to 1 . To correlate the effect of number and position of chlorine atoms on UV-visible spectra, we have presented UV-visible spectra of all the compounds in Scheme 1. A close look at the scheme 1 also sports the loss of conjugation in the twisted conformations of compounds.

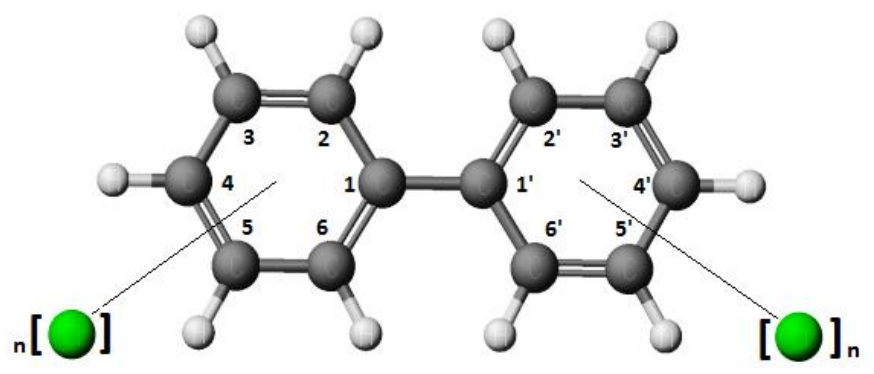

Figure 1. Structure of $\mathrm{PCB}$ 


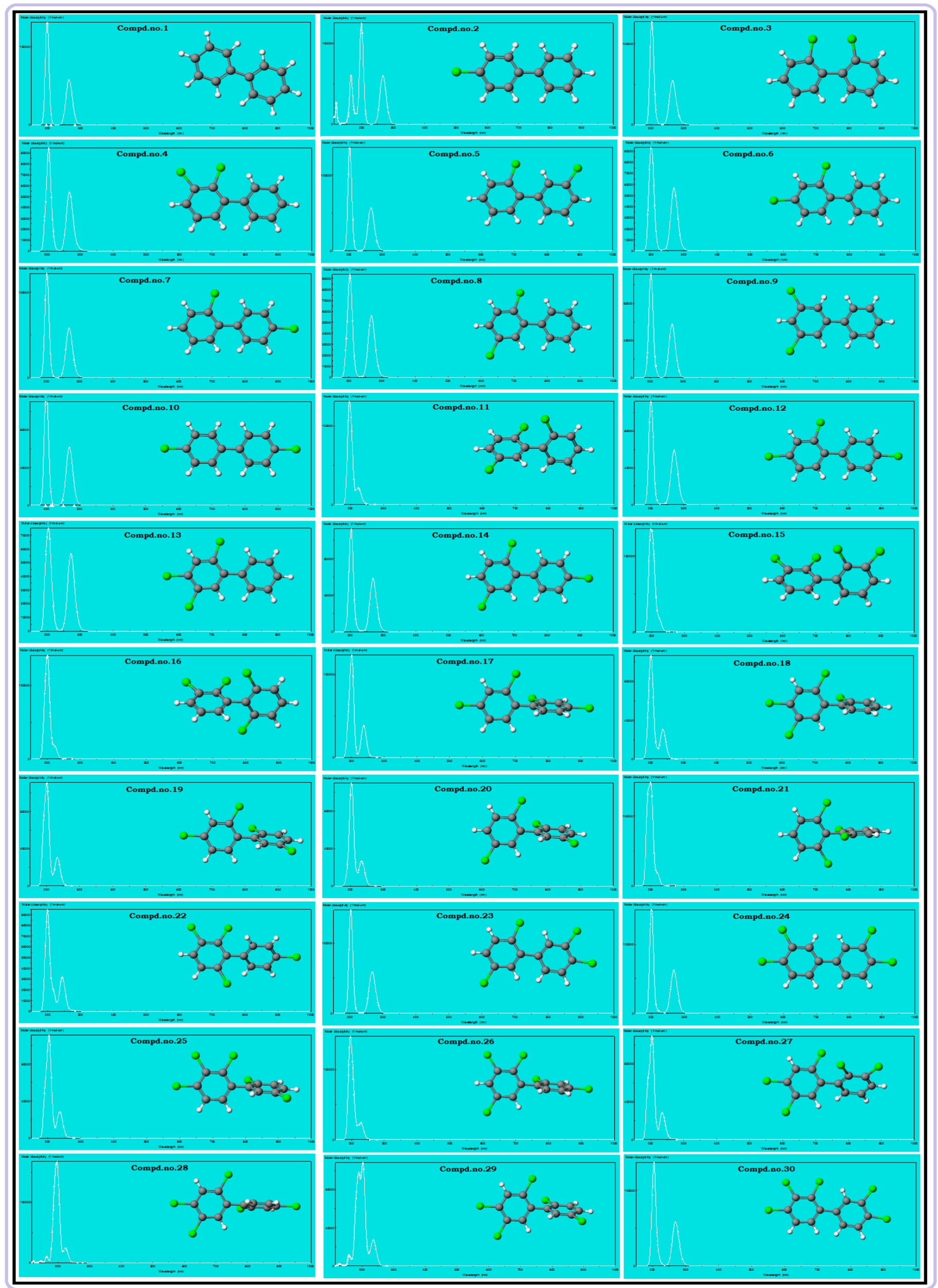




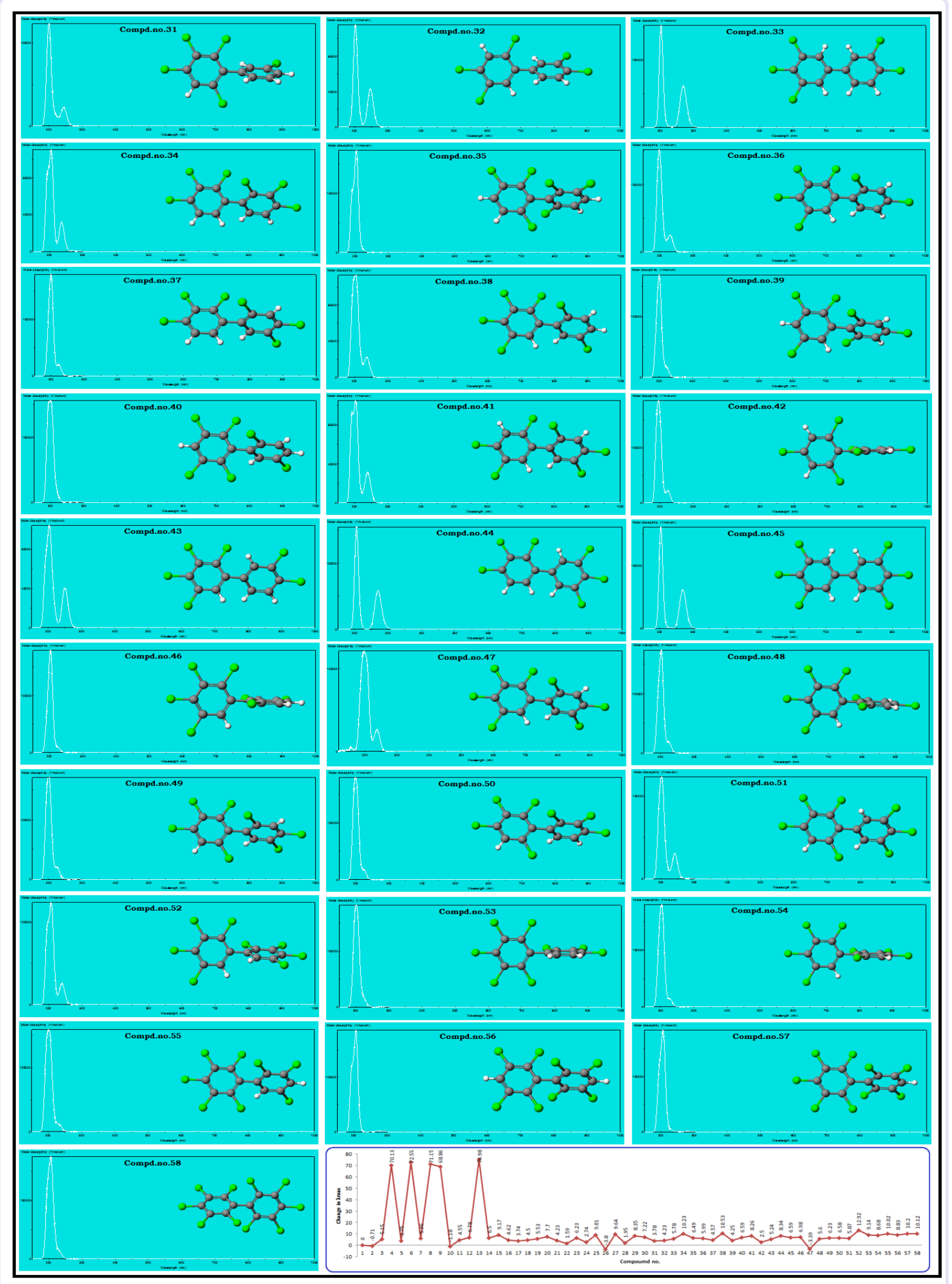

(b)

Scheme 1. (a) UV-visible spectra of compound no. 1-30; (b) UV-visible spectra of compound no. $31-58$ 


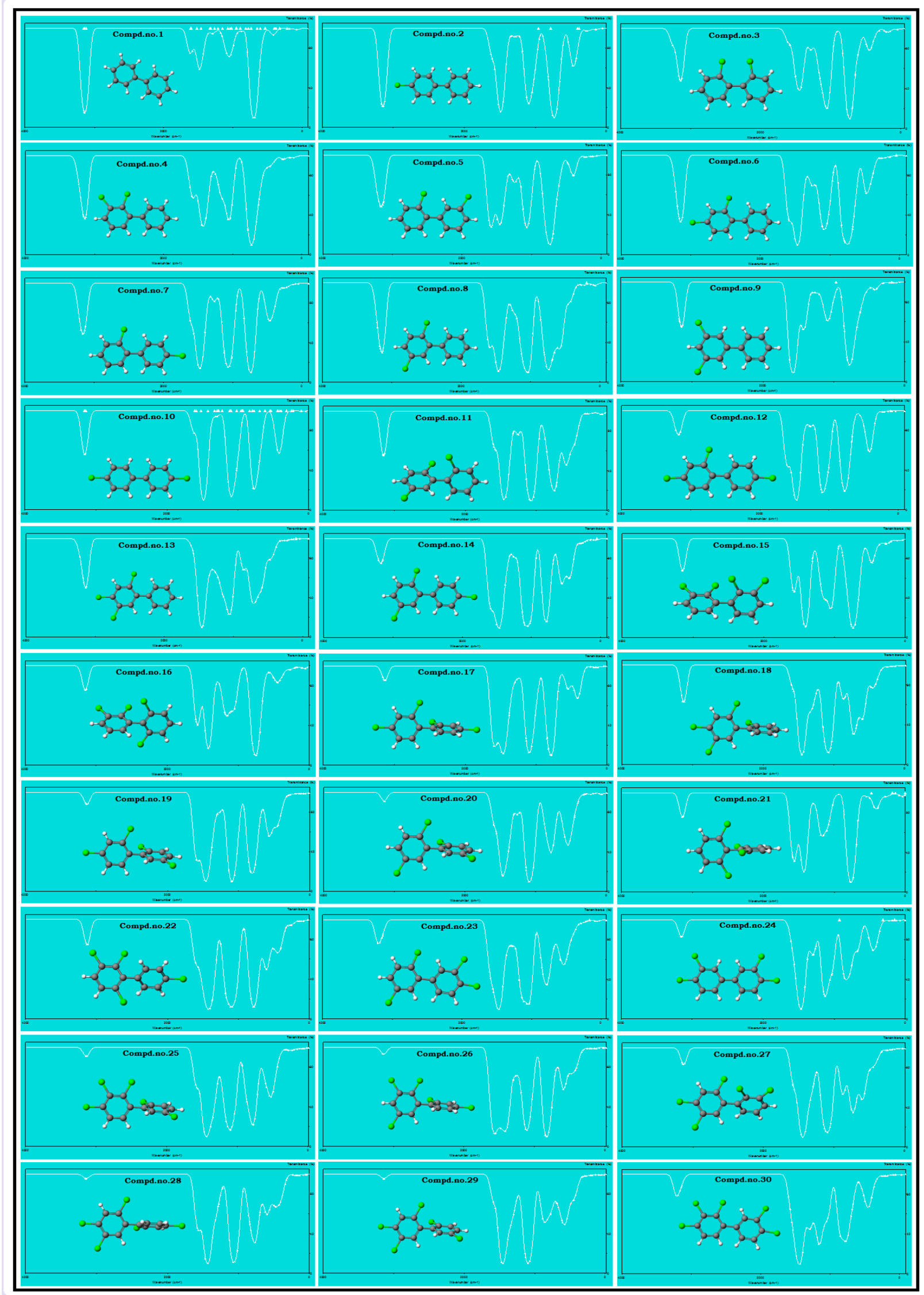

(a) 


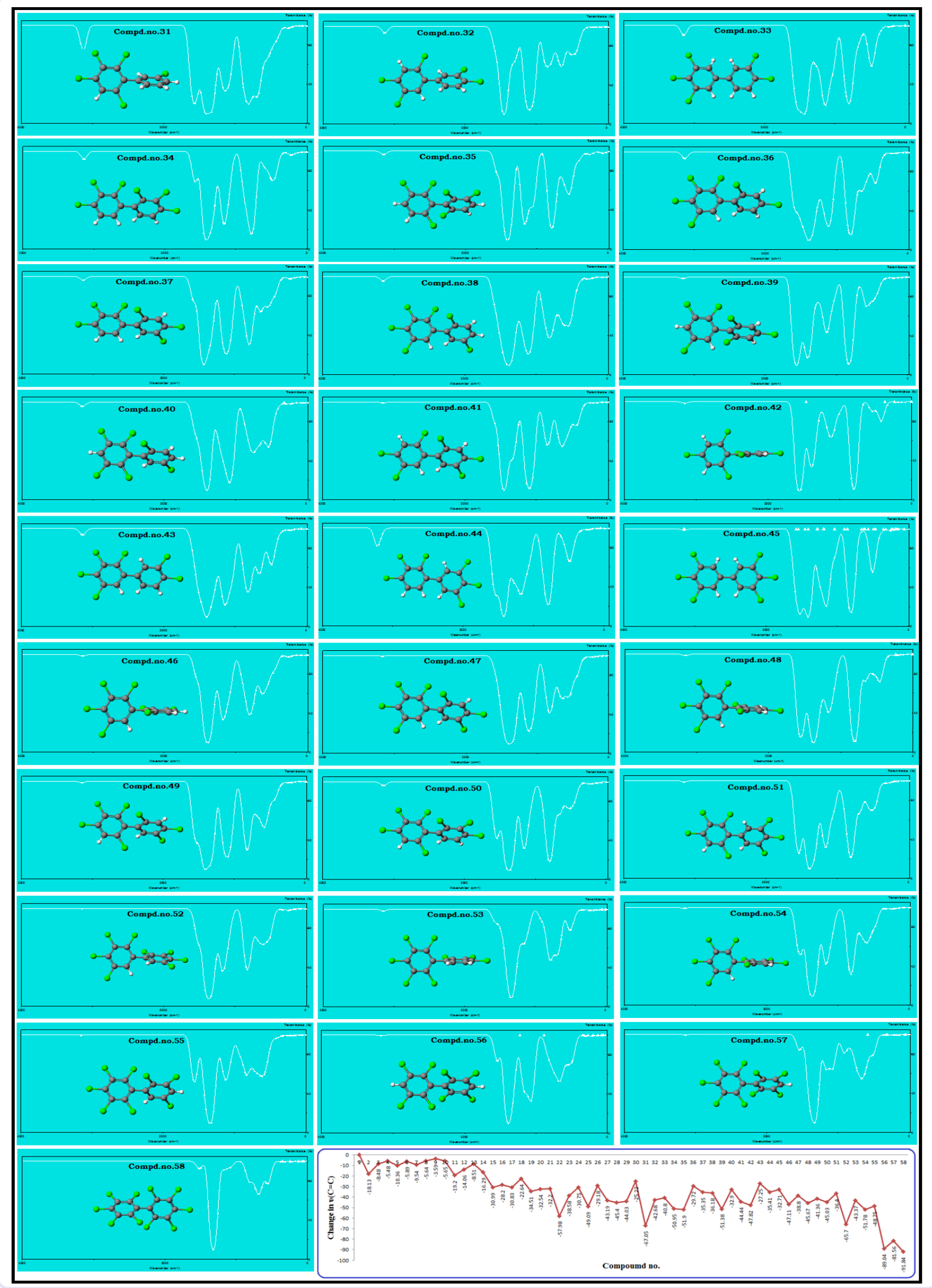

(b)

Scheme 2. (a) IR spectra of compound no. 1-30; (b) IR spectra of compound no. 31-58 
The calculated vibrational spectrum has proved to be a powerful tool to investigate changes in molecular aggregation, orientation, and structure at the level of functional groups [42]. Biphenyl and PCBs in the ground state have 60 fundamentals with various symmetries. Since almost all the vibrational modes are delocalized over whole molecule, they cannot be ascribed to several local vibrational motions. These are (IR tors), (IR str + $\mathrm{R}$ ip def), (R oop def), (R ip def + IR str + $\mathrm{CC}$ str), ( $\mathrm{CH}$ oop bend), (R ip def), (CC str), (CH ip bend), (IR str + $\mathrm{CH}$ ip bend), (CC str $+\mathrm{R}$ ip def) and ( $\mathrm{CH}$ str). This is the characteristic feature of aromatic compounds. For comparative study the IR spectra of all the compounds are placed in scheme 2 . Among the above modes, we have extracted CC str $+\mathrm{R}$ ip def i.e. $v(\mathrm{C}=\mathrm{C})$ and $\mathrm{CH}$ str i.e. $v(\mathrm{C}-\mathrm{H})$ for correlation with $\mathrm{BCF}$ and are tabulated in Table 2 .

Table 2. Calculated HOMO-LUMO gap, $\lambda_{\max }$ from UV-visible spectra and frequencies from IR spectra, experimental BCF and predicted BCF of PCBs

\begin{tabular}{|c|c|c|c|c|c|c|c|c|}
\hline S.N. & ${ }^{\mathrm{a}} \mu$ & $\begin{array}{l}\text { Dihedral } \\
\text { Angle }\left(^{\circ}\right)\end{array}$ & $\begin{array}{c}\text { HOMO- } \\
\text { LUMO } \\
\text { gap }\end{array}$ & $\lambda_{\max }(\mathrm{nm})$ & $v(C=C)$ & $v(\mathrm{C}-\mathrm{H})$ & $\log C_{\mathrm{Fexp}}$ & LogBCF pre \\
\hline 1 & 0 & 00.0 & 3.575 & 197.10 & 1624.70 & 3140.04 & 2.64 & 3.68 \\
\hline 2 & 2.005 & 00.1 & 3.434 & 196.39 & 1606.57 & 3145.50 & 2.77 & 4.26 \\
\hline 3 & 3.141 & 01.0 & 3.382 & 202.25 & 1616.22 & 3140.76 & 3.38 & 3.96 \\
\hline 4 & 2.667 & 00.0 & 3.502 & 267.23 & 1619.22 & 3130.48 & 4.11 & 3.96 \\
\hline 5 & 3.442 & 00.0 & 3.498 & 200.85 & 1614.34 & 3140.96 & 3.80 & 4.02 \\
\hline 6 & 2.076 & 00.1 & 3.430 & 269.65 & 1618.81 & 3140.01 & 3.55 & 3.98 \\
\hline 7 & 2.713 & 00.1 & 3.407 & 203.06 & 1615.16 & 3149.25 & 3.57 & 3.99 \\
\hline 8 & 0.789 & 00.1 & 3.485 & 268.25 & 1619.06 & 3131.92 & 3.89 & 3.97 \\
\hline 9 & 2.414 & 00.1 & 3.523 & 265.96 & 1621.11 & 3147.59 & 3.78 & 3.90 \\
\hline 10 & 0 & 00.1 & 3.308 & 195.92 & 1619.05 & 3145.20 & 3.28 & 3.86 \\
\hline 11 & 1.770 & 79.5 & 4.141 & 201.65 & 1605.50 & 3146.56 & 4.11 & 4.30 \\
\hline 12 & 1.295 & 00.1 & 3.291 & 203.88 & 1610.64 & 3149.07 & 4.20 & 4.14 \\
\hline 13 & 2.200 & 00.2 & 3.385 & 272.08 & 1616.19 & 3128.25 & 4.26 & 4.06 \\
\hline 14 & 1.168 & 00.2 & 3.346 & 203.60 & 1608.41 & 3148.91 & 4.23 & 4.21 \\
\hline 15 & 3.668 & 79.6 & 4.235 & 206.27 & 1593.71 & 3147.98 & 4.23 & 4.68 \\
\hline 16 & 2.875 & 82.2 & 4.214 & 201.72 & 1596.50 & 3144.20 & 4.84 & 4.59 \\
\hline 17 & 2.024 & 66.5 & 3.935 & 200.84 & 1593.87 & 3140.01 & 4.85 & 4.67 \\
\hline 18 & 2.845 & 67.6 & 3.929 & 201.60 & 1602.06 & 3135.16 & 5.00 & 4.41 \\
\hline 19 & 1.376 & 69.9 & 3.931 & 202.63 & 1590.19 & 3148.04 & 4.84 & 4.79 \\
\hline 20 & 0.409 & 66.6 & 3.857 & 204.80 & 1592.16 & 3149.73 & 4.63 & 4.73 \\
\hline 21 & 0.011 & 88.7 & 4.382 & 201.33 & 1592.50 & 3136.28 & 3.85 & 4.71 \\
\hline 22 & 2.050 & 61.5 & 3.777 & 198.69 & 1566.72 & 3140.25 & 4.60 & 5.54 \\
\hline 23 & 2.204 & 01.3 & 3.312 & 203.33 & 1586.12 & 3138.84 & 4.77 & 4.92 \\
\hline 24 & 2.542 & 00.3 & 3.250 & 199.84 & 1593.95 & 3141.00 & 4.59 & 4.67 \\
\hline 25 & 2.311 & 66.9 & 3.801 & 206.11 & 1575.61 & 3137.76 & 5.38 & 5.26 \\
\hline 26 & 1.611 & 76.7 & 4.000 & 193.30 & 1595.52 & 3147.36 & 5.00 & 4.61 \\
\hline 27 & 2.648 & 68.5 & 3.882 & 206.74 & 1581.51 & 3144.25 & 5.43 & 5.07 \\
\hline 28 & 1.309 & 82.9 & 3.844 & 199.05 & 1579.30 & 3136.62 & 5.00 & 5.13 \\
\hline 29 & 1.437 & 68.6 & 3.844 & 205.45 & 1580.67 & 3147.31 & 5.40 & 5.10 \\
\hline 30 & 3.152 & 00.1 & 3.224 & 204.32 & 1599.48 & 3140.77 & 5.00 & 4.50 \\
\hline 31 & 1.993 & 66.5 & 3.827 & 200.88 & 1557.65 & 3139.70 & 5.00 & 5.83 \\
\hline 32 & 1.282 & 54.2 & 3.644 & 201.33 & 1582.02 & 3142.06 & 5.00 & 5.05 \\
\hline 33 & 1.412 & 00.3 & 3.236 & 202.88 & 1583.90 & 3145.88 & 5.81 & 4.99 \\
\hline
\end{tabular}




\begin{tabular}{lllllllll}
34 & 3.269 & 68.7 & 3.880 & 207.33 & 1573.75 & 3145.81 & 5.77 & 5.32 \\
35 & 1.453 & 89.5 & 4.092 & 203.59 & 1572.80 & 3138.16 & 5.43 & 5.35 \\
$36^{*}$ & 1.928 & 77.5 & 3.971 & 203.09 & 1594.98 & 3149.85 & 5.88 & 4.64 \\
$37^{*}$ & 1.997 & 89.4 & 4.065 & 201.67 & 1589.35 & 3145.27 & 5.39 & 4.82 \\
$38^{*}$ & 2.049 & 70.7 & 3.801 & 207.63 & 1588.52 & 3144.43 & 5.81 & 4.85 \\
$39^{*}$ & 1.073 & 86.7 & 4.041 & 201.35 & 1573.32 & 3151.80 & 5.39 & 5.33 \\
$40^{*}$ & 0.472 & 89.7 & 3.919 & 203.69 & 1591.80 & 3150.06 & 5.54 & 4.74 \\
$41^{*}$ & 0.156 & 67.1 & 3.764 & 205.36 & 1580.26 & 3147.60 & 5.65 & 5.11 \\
$42^{*}$ & 0.004 & 88.6 & 4.382 & 199.60 & 1576.88 & 3154.16 & 4.93 & 5.21 \\
$43^{*}$ & 1.712 & 53.3 & 3.592 & 202.34 & 1597.45 & 3156.12 & 5.39 & 4.56 \\
$44^{*}$ & 2.096 & 01.1 & 3.218 & 205.44 & 1589.29 & 3141.73 & 5.39 & 4.82 \\
$45^{*}$ & 0.002 & 00.1 & 3.218 & 203.69 & 1591.99 & 3148.28 & 5.97 & 4.73 \\
46 & 2.751 & 88.7 & 4.060 & 204.08 & 1577.59 & 3147.04 & 5.80 & 5.20 \\
47 & 0.839 & 71.0 & 3.782 & 193.71 & 1585.90 & 3156.23 & 5.80 & 4.91 \\
48 & 1.823 & 88.5 & 4.057 & 202.70 & 1579.03 & 3146.02 & 5.80 & 5.15 \\
49 & 0.933 & 86.3 & 3.941 & 203.33 & 1583.34 & 3140.42 & 5.84 & 5.01 \\
50 & 2.193 & 89.0 & 4.114 & 203.68 & 1579.67 & 3158.18 & 5.80 & 5.13 \\
51 & 1.833 & 66.1 & 3.753 & 202.97 & 1588.30 & 3145.37 & 5.84 & 4.85 \\
52 & 1.101 & 69.4 & 3.744 & 210.02 & 1559.00 & 3145.42 & 5.81 & 5.80 \\
53 & 1.956 & 88.7 & 3.995 & 206.24 & 1581.33 & 3142.83 & 5.92 & 5.08 \\
54 & 1.529 & 85.5 & 3.961 & 205.78 & 1572.92 & 3144.99 & 5.92 & 5.35 \\
55 & 0.875 & 79.2 & 3.782 & 207.12 & 1575.95 & 3149.12 & 5.88 & 5.25 \\
56 & 0.002 & 89.8 & 3.937 & 205.93 & 1535.66 & 3167.46 & 5.82 & 6.54 \\
57 & 0.915 & 87.1 & 3.866 & 207.30 & 1543.14 & 3146.68 & 5.71 & 6.30 \\
58 & 0.006 & 82.2 & 3.791 & 207.22 & 1532.86 & 0.00 & 5.44 & 6.63 \\
\hline
\end{tabular}

aDipole moment of the compound, * compounds involved in test set

To correlate BCFs of the compounds with UV- and IR spectral data, we have performed multiple linear regression (MLR) analysis. For this electronic spectral data and vibration frequencies were used as independent variables and the experimental BCFs of the compounds as dependent variables. To test the predictive ability of the model, we have performed external cross validation model with leave-ten-out (L100) technique, where ten compounds are removed at a time and a number of models were generated and among them following model was found reliable.

$\operatorname{logBCF} F_{\text {pre }}=-0.0319944 \times v(C=C)+0.00151573 \times \lambda_{\max }+55.3602$

$\mathrm{R}^{2} \mathrm{~L} 100=0.650, \mathrm{R}^{2}$ adj $=0.642, \mathrm{se}=0.60, \mathrm{~F}=111.86, \mathrm{q}^{2} \mathrm{~L} 100=0.535$

where $v(C=C)$ is the first descriptor and $\lambda_{\max }$ is the second descriptors. $v(C=C)$ has negative descriptor coefficient magnitudes that shows indirect relationship with $\mathrm{BCF}$, while $\lambda_{\max }$ has positive descriptor coefficient magnitudes that shows direct relationship with BCF. The predicted BCF values as obtained from this model are also given in Table 2, while the trend of experimental and predicted BCF is shown in Figure 2.

Previously, we have also predicted the BCF of these compounds using DFT-method and the descriptors used were atomic in nature viz., partial atomic charges and HOMO densities [43]. The values of above descriptors were calculated at twelve sites of PCBs. And the study reflected that partial atomic charges have more reliable predicting power than the HOMO densities. The ability of these models was $\mathrm{r}^{2}$ between 0.645 and 0.916 for atomic charges and $\mathrm{r}^{2}$ between 0.638 and 0.840 for $\mathrm{HOMO}$ densities. And the $\mathrm{r}^{2} \mathrm{cv}$ for these 
models was 0.639 to 0.916 (atomic charge) and 0.614 to 0.693 (HOMO density). The s values for these models were 0.482 to 0.288 for atomic charges and 0.532 to 0.397 for HOMO densities. The reliable model with respect to atomic charge was:

$$
\begin{gathered}
\operatorname{logBCF} F_{\text {pre }}=1.65 \times \mathrm{Q}_{6}+3.82 \times \mathrm{Q}_{5}+3.56 \times \mathrm{Q}_{4}+4.68 \times \mathrm{Q}_{3}+4.326 \times \mathrm{Q}_{2}+0.425 \times \mathrm{Q}_{1}+1.25 \times \mathrm{Q}^{\prime}{ }^{\prime} \\
+7.78
\end{gathered}
$$

$\mathrm{r}^{2}=0.917, \mathrm{r}^{2} \mathrm{CV}=0.879, \mathrm{~s}=0.270, \mathrm{n}=56, \mathrm{k}=7$

While, the reliable model with respect to HOMO density was:
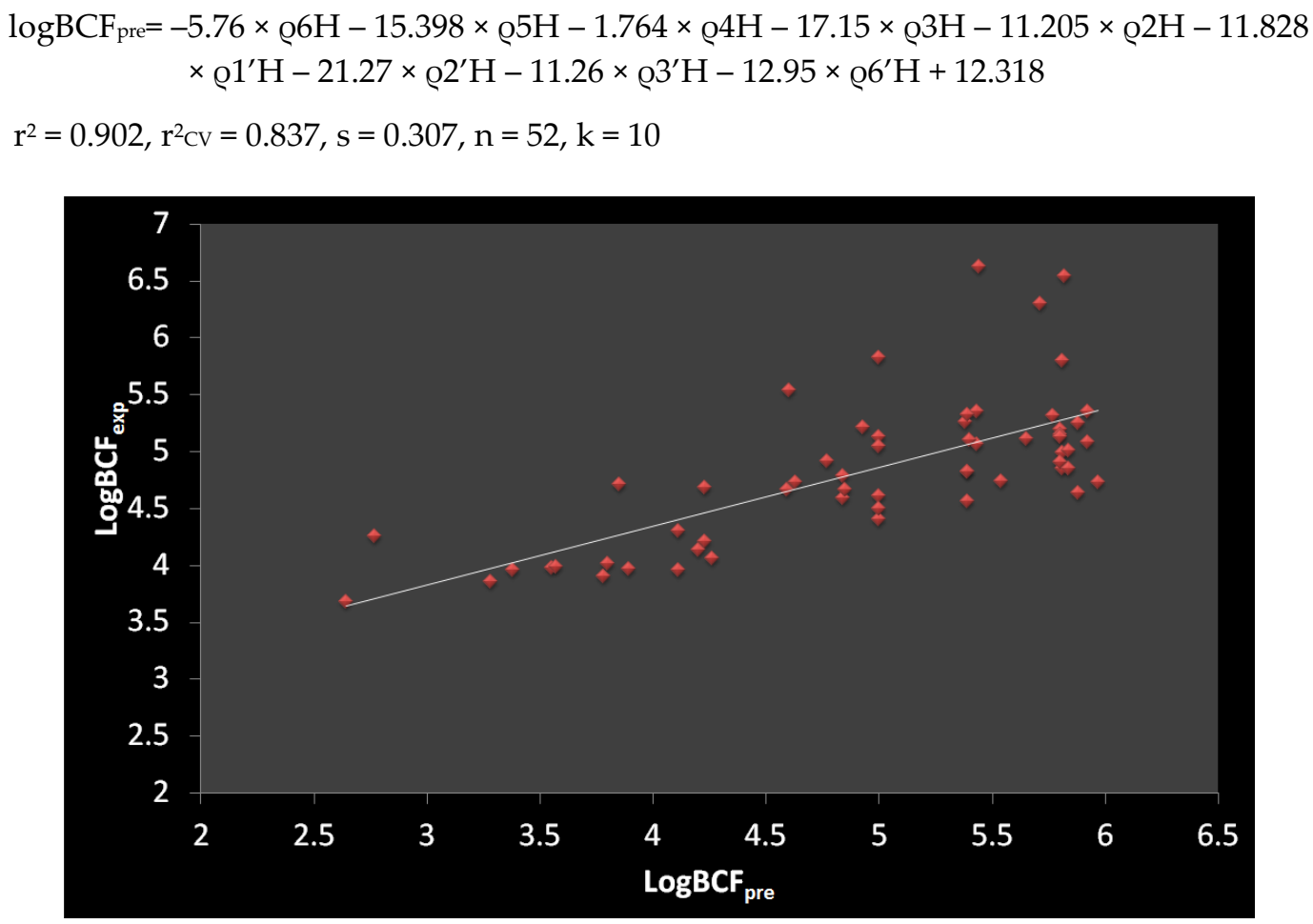

Figure 2. Trends of experimental $\left(\log B C F_{\exp }\right)$ and predected bioconcentration factors $\left(\log B C F_{p r e}\right)$

Further, we have also made DFT based prediction of BCF these compounds using molecular descriptors. The descriptors used were dipole moment $(\mu)$, ionization energy $(\mathrm{IE})$, electron affinity (EA), electronegativity $(\chi)$, hardness $(\eta)$, softness $(S)$ and electrophilicity index $(\omega)$ [44]. Here, the study reflected that $\mu$ and IP are reliable descriptors for correlation of BCF of PCBs with their electronic structures. The resulted model as shown below has $\mathrm{r}^{2}=0.914, \mathrm{r}^{2} \mathrm{CV}=0.898, \mathrm{~s}=0.267, \mathrm{n}=52, \mathrm{k}=2$

$$
\log B C F_{\mathrm{pre}}=0.0319265 \times \mu+3.68314 \times \text { IP }-17.7294
$$

A comparative study of these results shows that atomic and molecular properties are reliable descritors to predict the BCF of PCBs and can also made valuable contribution to descovered the methodology that help to degradate these persistants pollutants. While the spectroscopic data based descriptors help to find out the route and the mechanism that help to reduce the wealth and time for descovering the new pathway of the degradation of these persistant organic pollutants.

\section{Conclusion:}


On the basis of present study it has been concluded that DFT-based $v(\mathrm{C}=\mathrm{C})$ and $\lambda_{\max }$ have sufficient reliability to relate the bioconcentration factors of polychlorinated biphenyls with their structures. Thus UV-visible and IR-spectroscopic properties can be used to predict BCFs of a large number of related compounds within limited time without any difficulty and help to find out the route and the mechanism that help to reduce the wealth and time for descovering the new pathway of the degradation of these persistant organic pollutants.

\section{Acknowledgement}

The authors are thankful to Dr. O.P. Mishra, Ex.Principal M.L.K. (P.G.) College; Balrampur, for providing the laboratory facilities to conduct the calculation.

\section{References}

[1] V. K. Sahu and R. K. Singh, Prediction of bioconcentration factor of organic compounds in fish, Clean-soil, air, water, 3 (2009), pp. 850-857.

[2] R. G. Parr and W. Yang, Density functional theory of atoms and molecules, Oxford University Press, New York, p. 127, 1989.

[3] P. Geerlings, F. D. Proft and J. M. L. Martin, In Recent Developments in Density Functional Theory (Theoretical and Computational Chemistry) Seminario, S., Ed.; Elsevier: Amsterdam, vol. 5, pp.773-809, 1996.

[4] M. Karelson, V. S. Lobanov and A. R. Katritzky, Quantum-chemical descriptors in QSAR/QSAR research, Chem. Rev. 96 (1996), pp. 1027-1044.

[5] I. Grabowska, Polychlorinated Biphenyls (PCBs) in Poland: Occurance, Determination and Degradation, Polish J. of Environ. Stud. 19 (2010), pp. 7-13.

[6] R. F. Herrick, D. J. Lefkowitz, G. A. Weymouth, Soil contamination from PCB containing buildings, Environ. Health Persp. 115 (2007), pp. 173-175.

[7] S. K. Sahu, P. Y. Ajmal, G. G. Pandit and V. D. Puranik, Vertical distribution of polychlorinated biphenyl congeners in sediment core from Thane Creek area of Mumbai, India, J. Hazard Mater. 164 (2009), pp.1573-1579.

[8] K. Senthilkumar, K. Kannan, A. Subramanian and S. Tanabe, Accumulation of organochlorine pesticides and polychlorinated biphenyls in sediments, aquatic organisms, birds, bird eggs and bat collected from South India, Environ. Sci. Pollut. Res. 8 (2001), pp.35-47.

[9] B. Hope, S. Scatolini, E. Titus, Bioconcentration of chlorinated biphenyls in biota from the North Pacific Ocean, Chemosphere 36 (1938), pp. 1247-1261.

[10] T. Kunisue, M. Watanabe, A. Subramanian, A.M. Titenko, S. Tanabe, Congener-specific patterns and toxic assessment of polychlorinated biphenyls in resident and migratory birds from Southern India and Lake Baikal in Russia, Arch. Environ. Contam. Toxicol. 45 (2003), pp.547-561.

[11] G.M. Swanson, H.E. Ratcliffe and L.J. Fischer, Human exposure to policlorinated biphenyls (PCBs): A critical assessment of the evidence for adverse health effects, Regul. Toxicol. Pharmacol. 21 (1995), pp.136-150.

[12] G. Schade and B. Heinzow, Organochlorine pesticides and polychlorinated biphenyls in human milk of mothers living in northern Germany: current extent of contamination, time trend from 1986 to 1997 and factors that influence the levels of contamination, Sci. Total Environ. 215 (1998), pp.31-39.

[13] O. Faroon, D. Jones and C. De Rosa, Effects of polychlorinated biphenyls on the nervous system, Toxicol. Ind. Health, 16 (2000), pp.305-333.

[14] G. Devanathan, T. Isobe, A. Subramanian, K.A. Asante, S. Natrajan, P. Palanlappan, S. Takahashi and S. Tanabe, Contamination Status of Polychlorinated Biphenyls and Brominated Flame Retardants in Environmental and Biota Samples from India, Interdisciplinary Studies on Environmental Chemistry - Environmental Pollution and Ecotoxicology, Eds., M. Kawaguchi, K. Misaki, H. Sato, T. Yokokawa, T. Itai, T. M. Nguyen, J. Ono and S. Tanabe, pp. 269-277, 2012.

[15] G. Devanathan, A. Subramanian, M. Someya, A. Sudaryanto, T. Isobe, S. Takahashi, P. Chakraborty and S. Tanabe, Persistent organochlorines in human breast milk from major metropolitan cities in India, Environ. Pollut. 157 (2009), pp.148-154.

[16] I. Cok, A. Bilgili, M. Ozdemir, H. Ozbek, N. Bilgili, S. Burgaz, Organo-chlorine pesticides residues in human breast milk from agricultural regions of Turkey, 1995-1996, Bull. Environ. Contam. Toxicol. 59 (1997), pp.577-582.

[17] S. E. Bysshe, Bioconcentration Factor in Aquatic Organisms, in Handbook of Chemical Property Estimation Methods (Eds: W. J. Lyman, W. F. Reehl, D. H. Rosenblatt), McGraw Hill, New York, pp.5-30, 1982.

[18] G. Schüürmann and W. Klein, Advances in bioconcentration prediction, Chemosphere, 17 (1988), pp. 1551-1574.

[19] R. P. Davies and A. J. Dobbs, The prediction of bioconcentration in fish, Water Res. 18 (1984), pp. 1253-1262.

[20] D. Mackay, Correlation of bioconcentration factors, Environ. Sci. Technol. 16 (1982), pp.274-278. 
[21] S. Bintein, J. Devillers and W. Karcher, Nonlinear dependence of fish bioconcentration on n-octanol/water partition coefficient, SAR QSAR Environ. Res. 1 (1993), pp.29-39..

[22] A. Sabljic, H. Gusten, J. Hermens and A. Opperhuizen, Modeling octanol/water partition coefficients by molecular topology: chlorinated benzenes and biphenyls, Environ. Sci. Technol. 27 (1993), pp. 1394-1402.

[23] J. Devillers, S. Bintein and D. Domine, Comparison of BCF models based on logP, Chemosphere, 33 (1996), pp.1047-1065.

[24] S. Tao, H. Hu, X. Lu, R. W. Dawson and F. Xu, Fragment constant method for prediction of fish bioconcentration factors of nonpolar chemicals, Chemosphere, 41 (200), pp.1563-1568.

[25] P. Gramatica and E. Papa, QSAR modeling of bioconcentration factor by theoretical molecular descriptors, QSAR Comb. Sci. 22 (2003), pp.374-385.

[26] P. V. Khadikar, S. Singh, D. Mandloi, S. Joshi, A. V. Bajaj, QSAR study on bioconcentration factor (BCF) of polyhalogented biphenyls using the PI index, Bioorg. Med. Chem. 11 (2003), pp.5045-5050.

[27] J. C. Dearden and N. M. Shinnawei, Improved prediction of fish bioconcentration factor of hydrophobic chemicals, SAR QSAR Environ. Res., 15 (2004), pp.449-455.

[28] M. T. Sacan, S. S. Erdem, G. A. Ozpinar and I. A. Balcioglu, QSPR study on the bioconcentration factors of nonionic organic compounds in fish by characteristic root index and semi-empirical molecular descriptors, J. Chem. Inf. Comput. Sci. 44 (2004), pp.985-992.

[29] P. Gramatica and E. Papa, An update of the BCF QSAR model based on theoretical molecular descriptors, QSAR Comb. Sci. 24 (2005), pp.953-960.

[30] T. Ivanciuc, O. Ivanciuc and D. J. Klein, Modeling the bioconcentration factors and bioaccumulation factors of polychlorinated biphenyls with posetic quantitative super-structure/activity relationships (QSSAR), Mol. Divers. 10 (2006), pp. 133-145.

[31] L. T. Qin, S. S. Liu, H. L. Liu, H. L. Ge, A new predictive model for the bioconcentration factors of polychlorinated biphenyls (PCBs) based on the molecular electronegativity distance vector (MEDV), Chemosphere, 70 (2007), pp.1577-1587.

[32] C. Mori, H. Fukata, K. Sakurai, T. Jotaki, E. Todaka, Y. Saito, Strong correlation between the concentration of dioxins and total PCBs in current Japanese people, Chemosphere, 73 (2008), pp. 235-238.

[33] D. G. Wang, M. Yang, H. L. Jia, L. Zhou and Y. F. Li, Levels, distributions and profiles of polychlorinated biphenyls in surface soils of Dalian, China, Chemosphere, 73 (2008), pp. 38-42.

[34] A. R. Katritzky, M. Radzvilovits, S. Slavov, K. Kasemets, K. Tämm and Mati Karelson, Quantitative structure-activity relationship modeling of bioconcentration factors of polychlorinated biphenyls, Toxol. Environ. Chem. 92 (2010), pp. 1233-1247.

[35] E. Borges de Melo, A new quantitative structure-property relationship model to predict bioconcentration factors of polychlorinated biphenyls (PCBs) in fishes using E-state index and topological descriptors, Ecotox. Environ. Safe 75 (2012), pp. $213-222$.

[36] R. S. Chandrakumar and S. Pal, The Concept of Density Functional Theory Based Descriptors and its Relation with the Reactivity of Molecular Systems: A Semi-Quantitative Study, Int. J. Mol. Sci. 3 (2002), pp.324-337.

[37] P. Hohenberg and W. Khon, Inhomogeneous Electron Gas, Phys. Rev. 136 (1964), B864-B871.

[38] T. Ziegler, Approximate Density Functional Theoty as a practical tool in molecular energetics and dynamics, Chem. Rev. 91 (1991), pp.651-667.

[39] W. Koch and M.C. Holthausen, The Kohn-Sham approach, in: A Chemist's Guide to Density Functional Theory, Wiley-VCH, Weinheim, Germany, pp.41-64, 2002.

[40] M. Filatov and S. Shaik, Spin-restricted density functional approach to the open-shell problem, Chem. Phys. Lett., 288 (1998), pp.689-697.

[41] P.E. Siegbahn, and M.R.A. Blomberg, Density Functional Theory of biologically relevant metal centers, Annu. Rev. Phys. Chem., 50 (1999), pp.221-249.

[42] C. Topacli, A. Topacli, B. Tesneli, T. Richardson, G. Gümüs, V. Ahsen, Vibrational Spectrosc. 2006, 40, 20.

[43] A.K. Soni, V.K. Sahu and S. Sahu, DFT-based Prediction of Bioconcentration Factors of Polychlorinated Biphenys in Fish Using Atomic Descriptors. Asian J. Chem. 2017, 29, 2515-2521.

[44] A.K. Soni, P. Singh and V.K. Sahu, DFT-based Prediction of Bioconcentration Factors of Polychlorinated Biphenys in Fish Species Using Molecular Descriptors. Advances in Biological Chemistry, 10, 1-15. 